\title{
Navigating through the jungle of information. Informational self-efficacy predicts climate change-related media exposure, knowledge, and behaviour
}

\author{
Laura S. Loy ${ }^{1}$ (D) Karen R. S. Hamann ${ }^{1} \cdot$ Gerhard Reese $^{1}$
}

Received: 8 January 2020 / Accepted: 28 October 2020 / Published online: 25 November 2020

(C) The Author(s) 2020

\begin{abstract}
Climate change is a complex issue and understanding it is not an easy endeavour. An abundance of information is available through media and a lot of research has dealt with the question of how to best communicate this issue to the public. However, uncertainty and scepticism remain. In this paper, we argue that the subjective capability of informing oneself satisfactorily about climate change (i.e. informational self-efficacy) to reach goals like forming an opinion, evaluating political decisions regarding climate change, or behaving in a climate protective manner might be a crucial determinant of people's engagement with the issue. In an online survey with a quota sample of German residents $(N=498)$, informational self-efficacy positively predicted people's exposure to climate change communication in the media, their knowledge about the climate system and climate protective behaviours, and the extent to which they actually engaged in climate protective actions. Moreover, informational self-efficacy positively predicted climate protective behaviour and climate system knowledge indirectly through media exposure - but not behavioural knowledge. Hence, next to optimising the provided climate change communication, we suggest to strengthen people's confidence in dealing with it through media literacy trainings and examine the causal effect of these trainings on informational self-efficacy and climate change engagement. Furthermore, the impact of different behaviours on climate change should be more often and more concretely discussed in media coverage.
\end{abstract}

Keywords Climate change $\cdot$ Climate change knowledge $\cdot$ Pro-environmental behaviour $\cdot$ Media exposure $\cdot$ Self-efficacy

Laura S. Loy

loy@uni-landau.de

Extended author information available on the last page of the article 


\section{Introduction}

We live in a complex world and an abundance of available information tries to explain this world to us. A particularly complex and pressing challenge humanity is facing is global climate change (IPCC 2018). The vast majority of environmental scientists warn against devastating consequences if our societies will not succeed in reducing their $\mathrm{CO}_{2}$ emissions (Maibach et al. 2014; Ripple et al. 2017). At the same time, there are people who are sceptical about the anthropogenic causes of climate change and the potential of their own behavioural contribution to climate change mitigation (Capstick et al. 2015; Capstick and Pidgeon 2014; Hornsey et al. 2016; Tranter and Booth 2015).

Climate change is a complex topic due to its global scale, the long-term horizon, the invisibility of its causes, and the prognostic nature of associated research that unavoidably involves a degree of uncertainty (Moser 2010; Sterman 2011). Hence, understanding climate change is not an easy endeavour and a lot of research has dealt with the question of how to best communicate the issue to the public (e.g. Budescu et al. 2009; Curry 2011; Hart and Feldman 2016; Moser 2010; Patt and Weber 2014; Schenk and Lensink 2007; Whitmarsh and Lorenzoni 2010; Yohe and Oppenheimer 2011). Practical recommendations to convey information have been formulated (e.g. Corner and Clarke 2017; Shome and Marx 2009; Whitmarsh et al. 2011; Wibeck 2014).

However, little is known about whether people feel capable of receiving information and using the information they encounter in order to reach goals such as forming their own opinion, evaluating political decisions regarding climate change, or behaving in a climate protective manner. In this paper, we argue that the subjective capability of informing oneself satisfactorily about climate change (i.e. informational self-efficacy; see Loy et al. 2019) might be a crucial determinant of people's exposure to climate change communication in media, the scientific knowledge they gain about the issue, and their engagement in climate protective action. Hence, next to optimising the provided climate change communication, the importance of strengthening people's confidence in dealing with it might have been overlooked.

\section{Theoretical background}

\subsection{Informational self-efficacy as a predictor of media exposure}

The topic of climate change is often conveyed through mediated communication (Brüggemann et al. 2018; Ryghaug et al. 2011; Schmidt et al. 2013). People can come into contact with the issue both through active information search and through incidental exposure in their habitual media use (Arlt et al. 2010; Oschatz 2018). On the basis of Bandura's self-efficacy theory $(1977,1997)$, we propose that particularly informational self-efficacy plays a role for people's exposure to climate change communication in the media. By media exposure, we do not refer to a specific medium. Rather, we aim to grasp how much contact people have in general with the issue across diverse media outlets. Moreover, we do not differentiate between active search for climate change-related information and incidental exposure (e.g. Boczkowski et al. 2018; Gil de Zúñiga et al. 2017; Oeldorf-Hirsch 2018; Tewksbury et al. 2001). Rather, by asking people how much media contact they have with the topic climate change, we aim to cover both aspects simultaneously. Thereby, we 
aim to illuminate how much issue exposure people make and let happen, and whether this issue contact can be predicted by their informational self-efficacy.

Bandura (1977, p. 193) understands self-efficacy as "the conviction that one can successfully execute the behavior required to produce the [desired] outcomes." He emphasised self-efficacy as an important predictor of behaviour, because it equips an individual with confidence in his or her agency. Different self-efficacy concepts have been examined in the context of media use before. Hofstetter et al. (2001) investigated the belief in one's ability to effectively receive information with a certain medium termed media self-efficacy. In their study, they found that indeed, newspaper and television self-efficacy predicted the use of these information channels. Similarly, Schmitt et al. (2018) examined a concept named information-seeking self-efficacy. Referring to Bronstein (2014), it comprises mastery experiences when generally searching information, a positive comparison to others, social persuasion, and positive affect during information search. The more informationseeking self-efficacy people expressed, the less information overload in the context of online news consumption they reported (Schmitt et al. 2018).

While Schmitt et al. (2018) focused on efficacy beliefs about seeking information, Loy et al. (2019) extended this view to understanding and using information to achieve goals. They conceptualise informational self-efficacy as individuals' perceived capability to interact with information for purposes such as understanding an issue, forming an opinion, evaluating politics, or discussing with others. Thereby, they refer back to Bandura's (1977) aforementioned definition of self-efficacy as conviction of being able to execute behaviour (i.e. interacting with information) to produce certain outcomes (e.g. understanding an issue). While Bandura (1997) tends to focus on the behaviour part of his definition, our self-efficacy conceptualisation also incorporates various goals and thus has additional similarities to response efficacy (Doherty and Webler 2016). Given the abovementioned theoretical assumptions and empirical evidence, we suspect that people with stronger informational self-efficacy regarding the topic of climate change are more likely to confront themselves with respective information in the media. Accordingly, in a study by Loy et al. (2019), people's informational self-efficacy regarding political issues in general predicted their exposure to political contents in the Internet. We apply this concept to the specific topic of climate change. Due to scepticism about climate change, it appears additionally important whether people feel able to determine true facts about the issue. Pingree and colleagues introduced the concept of epistemic political efficacy, defined as the perceived ability to determine the truth behind (mediated) political debates (Pingree 2011; Pingree et al. 2013; Pingree et al. 2014). They found that epistemic political efficacy was positively related to the likelihood of seeking information on a political topic (Pingree 2011). Based on this research, we extended the concept of informational self-efficacy by including climate change-related epistemic goals.

In sum, prior research on political issues in general found that informational and epistemic selfefficacy predicted political media exposure. For the climate change issue, we similarly expected:

Hypothesis 1: Informational self-efficacy with regard to climate change positively predicts media exposure to the issue.

\subsection{Media exposure as a predictor of climate change-related knowledge and behaviour}

Next, we expected that media exposure to the issue of climate change is related to how much people know about it. Integrating the conceptualisation of environmental knowledge by Frick 
et al. (2004) with the conceptualisation of climate change knowledge by Tobler et al. (2012), we sought to differentiate between climate system knowledge and climate behavioural knowledge. While climate system knowledge comprises physical knowledge on $\mathrm{CO}_{2}$ and greenhouse gas emissions, the climate change phenomenon and its causes, as well as expected outcomes, climate behavioural knowledge covers knowledge about actions and their impact on climate change.

We assumed a link between media exposure and knowledge, because prior research found that news media appear to be a relevant source of information people consult to understand the issue of climate change (Ryghaug et al. 2011; Stamm et al. 2000). Moreover, as outlined above, recipients can come into contact with climate change not only through active information search on the topic but also without concrete intention through their habitual media use (Arlt et al. 2010; Oschatz 2018). We aimed to cover both, because prior research in the political domain found that not only active information search but also incidental exposure to political information in the media predicts people's political knowledge (e.g. Shehata et al. 2015; Tewksbury et al. 2001).

To date, few studies explicitly examined issue-specific media exposure and climate change knowledge. We did not find any study differentiating system and behavioural knowledge. Moreover, some studies only used subjective knowledge assessments. Looking at subjective climate change knowledge, Zhao (2009) found that the more participants generally used the Internet and newspapers, the more knowledgeable about climate change they considered themselves to be. The more attention people paid to media coverage of climate change, the higher their subjective knowledge (Ho et al. 2014). Kahlor and Rosenthal (2009) found that people's perceived understanding of climate change information received in the mass media was positively associated with how complex and accurately they defined the term global warming. Focusing on objective knowledge, a study by Taddicken (2013) indicated that climate change-related TV use but not radio, print, and Internet use correlated with climate change knowledge. Finally, in a longitudinal panel study by Oschatz (2018), information use in print media predicted objective knowledge gains while TV and online media exposure were unrelated.

The scarce evidence points towards media's potential to convey knowledge on the issue of climate change. While most of these studies addressed media channels separately, we were primarily interested in whether overall media exposure to the issue of climate change is related to knowledge. Kahlor and Rosenthal (2009) found that the more media channels people received climate change-related information from (i.e. a sum index covering Internet, radio, television, magazines, newspapers, and books), the more they knew about climate change. We expected:

Hypothesis 2: Media exposure to the issue of climate change positively predicts knowledge about the issue, in the form of climate system knowledge (H2a) and climate behavioural knowledge (H2b).

Furthermore, we also aimed to examine the relation between media exposure and people's engagement in climate protective behaviour. Drawing on conceptualisations of general proenvironmental behaviour, we understand it as individuals' ecological lifestyle with an impact on climate change. This includes private-sphere behaviours that determine one's carbon footprint in domains of transport, energy, and resource use, but also public-sphere behaviours such as being member of an organisation devoted to climate protection or discussing the issue of climate change with others (Kaiser and Wilson 2000, 2004; see also Stern 2000). 
We assumed a link between media exposure and climate protective behaviour, because a confrontation with the topic might raise problem awareness, which in turn is one of the key factors in models predicting pro-environmental behaviour (Bamberg and Möser 2007; Klöckner 2013). In line with this reasoning, participants in a qualitative focus group study by Happer and Philo (2016) reported an awareness that media coverage of climate change had decreased, which led them to perceive the issue as less of a priority and inhibited their motivation for behavioural change. In reverse conclusion, this might imply that more frequent media exposure could encourage behavioural engagement. Moreover, media might also concretely suggest which behaviours contribute to climate protection, even though we are not aware of content analyses examining how often this is the case.

Research on the relation between issue-specific media exposure and climate protective behaviour is also scarce. Taddicken (2013) examined media outlets separately. She did not find a relation between climate change-related TV, radio, print, and Internet use and support for climate protective policy measures (which can be regarded as public-sphere behaviour). Arlt et al. (2018) conducted a survey among German residents during the 21st Conference of the Parties (COP21) in Paris. They found that receiving information on the conference through social media (but not through TV and print) and active online information search were positively related to how much people engaged in online discussions on climate change. Concerning pro-environmental behaviour more generally, exposure to environmental issues through TV documentaries and interviews, print media, and Internet were positively related to environmental activism, while exposure to environmental TV campaigns/news/ads/series was a negative predictor in a study by Jiménez-Castillo and Ortega-Egea (2015). Finally, most similar to our research question, Huang (2016) found that climate-related media use (combined score including exposure and attention to respective information in television, newspapers, and Internet) predicted climate protective behaviour.

Even though evidence is mixed, when considering overall exposure to media instead of selected media channels, we suspected:

Hypothesis 2c: Media exposure to the issue of climate change positively predicts climate protective behaviour.

\subsection{Informational self-efficacy as a predictor of climate change-related knowledge and behaviour}

Finally, we expected that informational self-efficacy is positively related to climate change knowledge and climate protective behaviour. This assumption again goes back to Bandura's $(1977,1997)$ proposed link between self-efficacy and behaviour. We draw on a large research body looking at self-efficacy with a goal of protecting the environment or the climate. Many studies found that environmental or climate protective self-efficacy predicted climate protective behaviour in the private and the public sphere (e.g. Doherty and Webler 2016; Hamann and Reese 2020; Huang 2016; Kim and Choi 2005; Lee et al. 2014; Reese and Junge 2017). Yet, some studies did not find a relationship (e.g. Homburg and Stolberg 2006; Wang and Lin 2017) or found other predictors to be important instead (e.g. Chen 2015).

We reasoned that besides people's self-efficacy to protect the climate, their respective informational self-efficacy might determine their knowledge acquisition and how they eventually act. Empirical evidence on these relations is limited. In the study by Loy et al. (2019), 
informational self-efficacy regarding political issues predicted political knowledge directly and indirectly through political Internet use. Hofstetter et al. (2001) found that newspaper and television self-efficacy predicted political participation.

The outlined findings show a general trend that different types of self-efficacy predict knowledge and behaviour in the political and environmental domain. Based on these, we formulated the following hypothesis:

Hypothesis 3: Informational self-efficacy with regard to the issue of climate change positively predicts knowledge about the issue, in the form of climate system knowledge (H3a) and climate behavioural knowledge (H3b), and climate protective behaviour $(\mathrm{H} 3 \mathrm{c})$.

Moreover, we suspected that these relationships would be partly mediated by media exposure (cf. the indirect relation of informational self-efficacy and political knowledge through political Internet use found by Loy et al. 2019). This hypothesis is further backed by Huang's (2016) finding that self-efficacy to mitigate climate change indirectly predicted climate protective behaviour through climate-related media use:

Hypothesis 4: Informational self-efficacy with regard to the issue of climate change positively predicts climate system knowledge ( $\mathrm{H} 4 \mathrm{a})$, climate behavioural knowledge (H4b), and climate protective behaviour ( $\mathrm{H} 4 \mathrm{c})$ indirectly through more media exposure to the issue. The hypotheses are summarised in a figure in Supplement 1.

\subsection{Current research}

In the following, we report the analysis of the outlined research question. The data basis was embedded in a larger online survey study ${ }^{1}$ with a quota sample of the German population (for further results, see Loy 2018). The study included an informed consent and adhered to the ethical guidelines of the American Psychological Association.

\section{Method}

\subsection{Procedure and participants}

The market research institute Bilendi recruited participants who answered an online questionnaire programmed with the software package SoSci Survey (www.soscisurvey.de; Leiner, 2019). On the basis of the 2011 German census, we applied cross quotas for age group and gender as well as quotas for level of education in order to mirror the German population in these demographic characteristics. We excluded people who answered the questionnaire two standard deviations faster than the median (Leiner 2013). The final sample comprised $N=498$

\footnotetext{
${ }^{1}$ After demographics, participants answered questions on the psychological distance of climate change, the relevance attributed to the climate change issue, informational self-efficacy regarding the climate change issue, climate change knowledge, climate protective behaviour, the perceived communicated distance of climate change in news coverage, their contact with climate change-related communication via diverse channels including media channels and interpersonal contact, and social identity, including global identity.
} 
residents of Germany ( $n=257$ females, $M=48.7$ years of age, $S D=17.0$; information on a priori power analysis is provided in Supplement 2).

\subsection{Measures}

\subsubsection{Informational self-efficacy regarding the issue of climate change}

We adapted seven items on informational self-efficacy regarding political issues from Loy et al. (2019) to the specific topic of climate change. Moreover, we adapted three items on epistemic political efficacy from Pingree (2011) to the topic of climate change (see Supplement 4.1 for the German wording and Table 1 for a translation to English). Participants answered on Likert scales labelled from 1 (fully disagree) to 7 (fully agree).

We analysed the data using the statistical environment $R$ (see Supplement 3 for the packages used). In a first step, we conducted a one-dimensional confirmatory factor analysis (CFA) on all items. It did not yield satisfactory model fit (see Hair et al. 2014, and Supplement $3), \chi^{2}(35)=478.94, p<.001 ; \mathrm{CFI}=.76 ; \mathrm{TLI}=.69 ; \mathrm{RMSEA}=.160,90 \%$ CI $(.151, .169)$; $\mathrm{SRMR}=.100$.

In a second step, we calculated an exploratory factor analysis (EFA) to explore the underlying structure. Kaiser-Meyer-Olkin coefficients were between .86 and .96 and the items hence well suited. Parallel analysis (Horn 1965) suggested three factors (see Supplement 4.1 for details). Table 1 contains the results for the maximum likelihood factor analysis with oblique promax rotation extracting three factors, TLI $=.99, \mathrm{RMSEA}=.049,90 \%$ CI $(.027$, .069). It clearly differentiates the three factors without substantial cross-loadings.

We suggest to interpret these three factors as (1) an internal dimension of informational self-efficacy reflecting whether one feels capable of receiving information on climate change (i.e. understanding the topic, selecting information, forming an opinion), (2) an external dimension reflecting whether one feels capable of dealing with information in order to reach external goals (i.e. evaluating political decisions; discussing with others; explaining the topic

Table 1 Exploratory maximum likelihood factor analysis with oblique rotation for the informational self-efficacy items

\begin{tabular}{|c|c|c|c|c|}
\hline Item & $\begin{array}{l}\text { Factor } \\
\text { "internal" }\end{array}$ & $\begin{array}{l}\text { Factor } \\
\text { "external" }\end{array}$ & $\begin{array}{l}\text { Factor } \\
\text { "epistemic" }\end{array}$ & $\mathrm{h}_{2}$ \\
\hline \multicolumn{5}{|l|}{$\begin{array}{l}\text { I am able to inform myself sufficiently about the issue of } \\
\text { climate change to ... }\end{array}$} \\
\hline 1. ... understand the topic well. & .91 & -.01 & .02 & .85 \\
\hline 2. ... select the most important information. & .90 & .02 & -.00 & .82 \\
\hline 3. ... form an opinion. & .67 & .03 & .21 & .75 \\
\hline 4. ... evaluate respective political decisions. & .12 & .60 & .12 & .61 \\
\hline 5. ... discuss with others about it. & .22 & .75 & -.11 & .75 \\
\hline 6. ... explain the topic to others. & -.07 & .94 & .04 & .83 \\
\hline 7. ... behave in a climate protective manner. & .07 & .66 & .03 & .53 \\
\hline $\begin{array}{l}\text { 8. I feel confident that I can find the truth about the issue of } \\
\text { climate change. }\end{array}$ & .03 & -.03 & .84 & .70 \\
\hline $\begin{array}{l}\text { 9. Even though information on climate change seems } \\
\text { contradictory at first, I can figure out the basic facts. }\end{array}$ & -.01 & -.02 & .95 & .86 \\
\hline $\begin{array}{l}\text { 10. I am capable of finding objective facts about the issue } \\
\text { of climate change. }\end{array}$ & .00 & .10 & .81 & .77 \\
\hline$\%$ of variance & 24.7 & 26.4 & 23.7 & \\
\hline
\end{tabular}


to others; behaving in a climate protective manner), and (3) an epistemic dimension reflecting whether one feels capable of determining truth (i.e. reliable and objective facts). A descriptive analysis revealed that internal informational self-efficacy was highest in the sample $(M=5.29$, $S D=1.08)$, followed by external $(M=4.96, S D=1.13)$ and epistemic self-efficacy $(M=4.35$, $S D=1.21$ ). The correlation between the internal and external factor was $r=.79$, between the internal and epistemic factor $r=.54$, and between the external and epistemic factor $r=.64$. These high correlations suggest a second-order factor.

In a third step, we therefore calculated a CFA for a three-dimensional model with superordinate factor which yielded excellent model fit, $\chi^{2}(32)=67.30, p<.001$; CFI $=.98$; $\mathrm{TLI}=.97$; RMSEA $=.047,90 \% \mathrm{CI}(.035, .059)$; SRMR $=.032$. We used this model for the further analyses (for further analyses regarding the scale, see Supplement 4.1).

\subsubsection{Media exposure to the issue of climate change}

On the basis of measures by Taddicken (2013) and Trepte et al. (2017), we asked participants how often they had come into contact with information about climate change in nine media outlets (i.e. private TV channels, public TV channels, radio, regional newspapers, supraregional newspapers, weekly newspapers, brochures, academic journals, Internet) from 1 (never) to 6 (several times a week; for detailed results, see Supplement 4.2). We used the wording "contact with" to include not only active information search but also incidental information exposure through habitual media use.

We built a sum index for media exposure via the nine channels (see Kahlor and Rosenthal 2009). Missing values on the single items were 1 or $2 \%$ and we applied an expectation maximisation (EM) algorithm for ordinal data to replace these missing values (see Schafer and Graham 2002). One person had to be excluded from further analyses because of missing values for all media exposure items.

\subsubsection{Climate change knowledge}

We used a climate change knowledge scale developed by Tobler et al. (2012), revised by Shi et al. (2015), and extended it with adapted items from Kaiser and Frick (2002) and Frick et al. (2004). Participants evaluated 17 correct and 17 incorrect statements as "true", "false", or "do not know" and we coded their answers as 1 (correct) or 0 (incorrect, do not know).

Climate system knowledge covered $\mathrm{CO}_{2}$ and the greenhouse effect (e.g. "Burning oil, among other things, produces $\mathrm{CO}_{2}$ "), climate change and its causes (e.g. "The increase of greenhouse gases is mainly caused by human activities"), and expected consequences (e.g. "For the next few decades, the majority of climate scientists expect an increase in extreme events, such as droughts, floods, and storms"). Climate behavioural knowledge covered climate-related actions (e.g., "To let in fresh air in winter, it is most climate friendly to keep a window open for a while", reverse-coded), and the relative effectiveness of climate-related actions (e.g. "The production of meat and dairy products results in more $\mathrm{CO}_{2}$ emissions per $\mathrm{kg}$ food than the production of vegetables"). Unfortunately, however, we could not use the action effectiveness items due to a programming mistake (see Supplement 4.3).

A Rasch analysis (Bond and Fox 2007; see Supplement 4.4 for details) of all items resulted in a scale with a person separation reliability of $R_{p}=.90$. Item mean square infit values were between 0.80 and 1.18 and thus all below the recommended threshold of 1.30 for samples smaller than 500 as well as the threshold of 1.20 for samples between 500 and 1000 
participants. A separate analysis of climate system knowledge (21 items) resulted in a scale with a person separation reliability of $R_{p}=.88$. Item mean square infit values were between 0.82 and 1.12. A separate analysis of climate behavioural knowledge ( 7 items as the items on effectiveness knowledge could not be used) resulted in a scale with a person separation reliability of $R_{p}=.65$. Item mean square infit values were between 0.80 and 1.18 . Even though the latter scale is not optimal due to the reduced item number, we used the person estimates of the separate scales for further analyses in order to reveal possible differences between system and behavioural knowledge.

\subsubsection{Climate protective behaviour}

To measure climate protective behaviour, we adapted several versions of the General Ecological Behaviour Scale (e.g. Kaiser and Wilson 2000, 2004). Participants indicated how often they conducted 25 actions (never, seldom, once in a while, often, very often; e.g. "I refrain from eating meat") and whether they conducted 10 further actions (yes, no; e.g., "I purchase green electricity"). The actions included mobility (e.g. "I fly within Germany"), energy use (e.g. "I use a clothes dryer"), consumption (e.g. "I buy seasonal fruits and vegetables"), and public actions ("I contribute financially to climate protection organisations"). As recommended by Kaiser and Wilson $(2000,2004)$, we dichotomised the items for Rasch modelling as 0 (never, seldom, once in a while; no) or 1 (often, very often; yes) for climate protective behaviours and as 0 (once in a while, often, very often; yes) or 1 (never, seldom; no) for climate damaging behaviours. As missing data can be handled by Rasch models, we provided the answer option cannot answer for participants to indicate that actions are not applicable to their living situation. Ten people had missing values on too many variables though and we needed to exclude them from the analysis as no person estimate could be determined. Rasch modelling yielded a satisfactory person separation reliability of $R_{p}=.73$. Item mean square infit values were between 0.83 and 1.18 . Table 2 summarises the satisfactory psychometric properties of the measures.

\section{Results}

Bivariate correlations between all variables are provided in Supplement 5.1. An analysis differentiating the diverse media channels is provided in Supplement 5.2. We tested the research hypotheses with a structural equation model (SEM). We allowed knowledge and behaviour to covary as we considered this as theoretically plausible (Díaz-Siefer et al. 2015; Frick et al. 2004; Kaiser and Frick 2002; Shi et al. 2015). The model fit the data well, $\chi^{2}(68)=$ 162.32, $p<.001 ; \mathrm{CFI}=.97 ; \mathrm{TLI}=.96 ; \mathrm{GFI}=.94 ; \mathrm{RMSEA}=.053,90 \%$ CI $(.044, .063)$; $\mathrm{SRMR}=.036$ (see Fig. 1 ; for statistical details, see Table 3$)^{2}$

Informational self-efficacy with regard to the issue of climate change positively predicted how much exposure people had to the issue through media ( $\mathrm{H} 1$, direct relation $\beta=.32$ ), how much they knew about the climate system (H3a, direct relation $\beta=.34$, total relation $\beta=.38$ )

\footnotetext{
${ }^{2}$ Please note that any difference between the data and the model stems from estimating informational selfefficacy (i.e. the latent measurement model). The structural part of the model is saturated and thus necessarily shows a perfect fit. As such, we do not interpret the model fit as a statistical test of our theoretical model. Instead, we use the model to estimate the values of the parameters while controlling for theoretically plausible covariates.
} 
Table 2 Psychometric properties of the measures

\begin{tabular}{|c|c|c|c|c|c|c|c|c|c|}
\hline Variable & $n$ & $M$ & $S D$ & Range & Items & $\alpha$ & $\omega$ & AVE & $R_{P}$ \\
\hline Informational self-efficacy & 498 & 4.88 & 1.00 & $1.60-7.00$ & 10 & .93 & .96 & .73 & - \\
\hline Internal & 498 & 5.29 & 1.08 & $1.33-7.00$ & 3 & .92 & .92 & .80 & - \\
\hline External & 498 & 4.96 & 1.13 & $1.50-7.00$ & 4 & .89 & .89 & .67 & - \\
\hline Epistemic & 498 & 4.35 & 1.21 & $1.00-7.00$ & 3 & .91 & .91 & .77 & - \\
\hline Media exposure (sum index) & $497 \mathrm{~b}$ & 26.57 & 10.00 & $9-54$ & 9 & - & - & - & - \\
\hline Climate system knowledge a & 498 & 0.02 & 1.57 & $-4.32-4.30$ & 21 & .84 & - & - & .88 \\
\hline Climate behavioural knowledge $^{a}$ & 498 & 0.23 & 1.68 & $-3.44-3.77$ & 7 & .65 & - & - & .65 \\
\hline Climate protective behaviour a & $488^{c}$ & -0.34 & 0.88 & $-3.54-2.60$ & 35 & .74 & - & - & .73 \\
\hline
\end{tabular}

$\alpha$, Cronbach's alpha; $\omega$, Raykov's omega; $R_{P}$, Rasch-based person separation reliability; $A V E$, average variance extracted

a Results are based on Rasch analyses

${ }^{b}$ One case with missing values for all media channels was excluded

c 10 cases with missing values for all variables were excluded

and climate protective behaviours ( $\mathrm{H} 3 \mathrm{~b}$, direct relation $\beta=.24$, total relation $\beta=.24$ ), and how much climate protective behaviour they reported $(\mathrm{H} 3 \mathrm{c}$, direct relation $\beta=.36$, total relation $\beta=.41$ ). These relations were of medium size. Media exposure to the issue of climate change positively predicted climate system knowledge $(\mathrm{H} 2 \mathrm{a}$, direct relation $\beta=.12)$ and climate protective behaviour ( $\mathrm{H} 2 \mathrm{c}$, direct relation $\beta=.13$ ), but not participants' knowledge about climate protective behaviours $(\mathrm{H} 2 \mathrm{~b})$. The relations were small. Accordingly, informational self-efficacy indirectly predicted only climate system knowledge $(\mathrm{H} 4 \mathrm{a}, \beta=.04)$ and climate protective behaviour $(\mathrm{H} 4 \mathrm{c}, \beta=.04)$ but not behavioural knowledge $(\mathrm{H} 4 \mathrm{~b})$ through more media exposure to the issue. These indirect relations were small but significant.

As an additional analysis, we repeated the analysis three times for the separate dimensions of informational self-efficacy as predictors (for detailed results, see Supplement 5.3). These analyses showed that internal, external, and epistemic informational self-efficacy each predicted how much exposure people had to the issue through media $(\mathrm{H} 1$; direct relations, $\beta=.60 / .70$ / .58 , respectively; $p \mathrm{~s}<.05)$. Internal, external, and epistemic informational self-efficacy predicted how much people knew about the climate system (H3a; direct relations, $\beta=.28 / .21 / .13$; indirect relations through media exposure, $\beta=.11 / .14 / .16$; total relations, $\beta=.39 / .35 / .29$, respectively; $p s<.05)$. Internal and external self-efficacy predicted climate behavioural

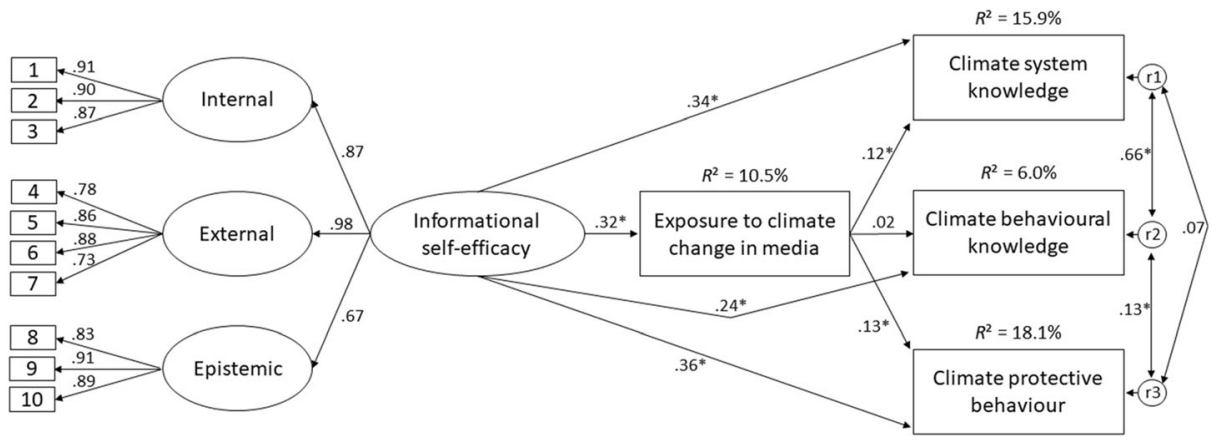

Fig. 1 Structural equation model. Standardised coefficients are displayed. The relations between climate system knowledge, climate behavioural knowledge, and climate protective behaviour represent residual covariances. $* p<.05$ 
knowledge directly $(\mathrm{H} 3 \mathrm{~b}$; direct relations, $\beta=.22 / .20, p \mathrm{~s}<.05$; no indirect relations through media exposure, $\beta=.02 / .02$, $n s$.; total relations, $\beta=.25 / .23$, $p \mathrm{~s}<.05$ ), while epistemic selfefficacy predicted it indirectly (direct relation, $\beta=.09$, $n s$.; indirect relation through media exposure, $\beta=.07$; total relation, $\beta=.16 ; p \mathrm{~s}<.05)$. Internal, external, and epistemic selfefficacy predicted how climate protective participants reported behaving $(\mathrm{H} 3 \mathrm{c}$; direct relations, $\beta=.18 / .32 / .12$; indirect relations through media exposure, $\beta=.14 / .09 / .16$; total relations, $\beta=.32 / .41 / .28 ; p \mathrm{~s}<.05)$.

In sum, when regarding the sizes of the relations, these findings suggest that the internal and external dimensions of self-efficacy might be most relevant to gain climate knowledge, the external dimension to take climate protective actions, while the epistemic dimension appears comparably less important.

\section{Discussion}

Climate change is a complex issue and people are confronted with a wealth of information on the topic. We tested whether people's subjective capability of informing themselves satisfactorily about climate change (i.e. informational self-efficacy) to reach goals like forming an opinion, evaluating political decisions regarding climate change, behaving in a climate protective manner, or determining true facts about the topic is related to their engagement

Table 3 Results of the structural equation model

\begin{tabular}{|c|c|c|c|c|c|c|}
\hline & Hypothesis & $B$ & $S E$ & $p$ & $95 \% \mathrm{CI}$ & $\beta$ \\
\hline H1 & Direct path: informational self-efficacy - media exposure & 3.58 & .56 & $<.001$ & $(2.49,4.67)$ & $.32 *$ \\
\hline $\mathrm{H} 2 \mathrm{a}$ & Direct path: media exposure - climate system knowledge & .02 & .01 & $.018^{\mathrm{a}}$ & $(.003, .03)$ & $.12 *$ \\
\hline $\mathrm{H} 2 \mathrm{~b}$ & $\begin{array}{l}\text { Direct path: media exposure - climate behavioural } \\
\text { knowledge }\end{array}$ & .00 & .01 & .705 & $(-.01, .02)$ & .02 \\
\hline $\mathrm{H} 2 \mathrm{c}$ & $\begin{array}{l}\text { Direct path: media exposure - climate protective } \\
\text { behaviour }\end{array}$ & .02 & .00 & .003 & $(.004, .02)$ & $.13^{*}$ \\
\hline $\mathrm{H} 3 \mathrm{a}$ & $\begin{array}{l}\text { Direct path: informational self-efficacy - climate } \\
\text { system knowledge }\end{array}$ & .57 & .08 & $<.001$ & $(.42, .73)$ & $.34 *$ \\
\hline $\mathrm{H} 3 \mathrm{~b}$ & $\begin{array}{l}\text { Direct path: informational self-efficacy - climate } \\
\text { behavioural knowledge }\end{array}$ & .42 & .09 & $<.001$ & $(.24, .61)$ & $.24 *$ \\
\hline $\mathrm{H} 3 \mathrm{c}$ & $\begin{array}{l}\text { Direct path: informational self-efficacy - climate } \\
\text { protective behaviour }\end{array}$ & .36 & .05 & $<.001$ & $(.25, .46)$ & $.36^{*}$ \\
\hline $\mathrm{H} 4 \mathrm{a}$ & $\begin{array}{l}\text { Indirect path: informational self-efficacy - media } \\
\text { exposure - climate system knowledge }\end{array}$ & .06 & .03 & $.024^{\mathrm{a}}$ & $(.01, .12)$ & $.04 *$ \\
\hline $\mathrm{H} 4 \mathrm{~b}$ & $\begin{array}{l}\text { Indirect path: informational self-efficacy - media } \\
\text { exposure - climate behavioural knowledge }\end{array}$ & .01 & .03 & .705 & $(-.04, .07)$ & .01 \\
\hline \multirow[t]{4}{*}{$\mathrm{H} 4 \mathrm{c}$} & $\begin{array}{l}\text { Indirect path: informational self-efficacy - media } \\
\text { exposure - climate protective behaviour }\end{array}$ & .04 & .01 & .005 & $(.01, .07)$ & $.04 *$ \\
\hline & $\begin{array}{l}\text { Total path: informational self-efficacy - climate } \\
\text { system knowledge }\end{array}$ & .64 & .07 & $<.001$ & $(.49, .78)$ & $.38^{*}$ \\
\hline & $\begin{array}{l}\text { Total path: informational self-efficacy - climate } \\
\text { behavioural knowledge }\end{array}$ & .43 & .09 & $<.001$ & $(.27, .61)$ & $.24 *$ \\
\hline & $\begin{array}{l}\text { Total path: informational self-efficacy - climate } \\
\text { protective behaviour }\end{array}$ & .40 & .05 & $<.001$ & $(.30, .50)$ & $.41^{*}$ \\
\hline
\end{tabular}

Confidence intervals (CI) were bootstrapped through 5000 samples

a These relations become insignificant if we apply a Bonferroni correction for multiple hypotheses testing ${ }^{*} p<.05$ 
with the issue. Indeed, informational self-efficacy of our German participants positively predicted their exposure to climate change communication in the media, their knowledge about the climate system and climate protective behaviours, and the extent to which they actually engaged in climate protective actions. Moreover, informational self-efficacy positively predicted climate protective behaviour and climate system knowledge indirectly through media exposure - but not behavioural knowledge. Our study underpinned that self-efficacy plays a crucial role in predicting climate protective behaviour and also knowledge about climate change.

An abundance of research shows that self-efficacy in different behavioural domains predicts related behaviours such as political self-efficacy predicting political participation (Caprara et al. 2009), Internet self-efficacy predicting Internet use (Eastin and LaRose 2000), or selfefficacy to engage in pro-environmental mobility behaviours predicting intentions to use sustainable transport options (Jugert et al. 2016). By investigating informational self-efficacy related to climate change, we contribute to a new research stream examining different selfefficacy goals that explicitly go beyond the general goal "to promote climate protection" (see Hamann and Reese 2020; Hanss and Böhm 2010). Therein, we empirically undergird a debate about how self-efficacy can be conceptualised and measured in a way so that operationalisations of independent and dependent variables are not too close (e.g. selfefficacy to behave pro-environmentally predicting pro-environmental behaviour; for a critique, see Williams and Rhodes 2016). Our findings show that not only for climate change knowledge (which is conceptually rather close to informational self-efficacy) but also for climate protective behaviour (which is a more remote concept), it seems relevant to feel capable of handling climate information.

We infer from these findings that it appears important to strengthen people's confidence in handling climate change news before exposing them to even more climate change information. By strengthening informational self-efficacy, also a rising climate scepticism might be banned. We would like to highlight that the external dimension of informational self-efficacy, which is the ability to inform oneself to evaluate political decisions, to engage in climate debates, and to act in a climate protective manner, was most strongly related to climate protective behaviour in our study. Hence, supporting people in using information for discussing the issue with others and for inferring relevant actions might be specifically fruitful.

\subsection{Limitations and future perspective}

The first limitation of this study is its cross-sectional design which does not allow causal conclusions. We do not know whether informational self-efficacy promotes media exposure, knowledge, and climate protective behavioural engagement, whether causal directions are vice versa, or caused by unconsidered third variables. Yet, this is the first study uncovering their interrelations. Follow-up studies could employ longitudinal designs and thereby examine whether so-called reinforcing spirals occur (Slater 2007): Possibly, media exposure predicts knowledge, which in turn motivates further media use directly or also indirectly via environmental concern (see Zhao 2009). There might be a similar spiral with regard to informational self-efficacy, namely frequent media exposure strengthening the confidence in dealing with the received information (i.e. informational self-efficacy), which in turn encourages further media use, knowledge, and consequently mitigating behaviours. Moreover, an interesting study by Geiger et al. (2017) found that an intervention conveying scientific knowledge on climate change strengthened people's self-efficacy to discuss climate change, which in turn predicted 
their actual engagement in discussions as a public-sphere behaviour (study 1). In study 2, they found that the amount of exposure to information on climate change in informal science learning centres predicted their knowledge on the issue, which in turn predicted their selfefficacy to discuss climate change as well as their response efficacy, defined as the perceived likelihood that discussions on climate change motivate societal action. Both forms of efficacy, in turn, predicted how frequently people actually discussed. Hence, their research points to a possible causal direction leading from knowledge gains to higher efficacy beliefs and to more public-sphere behaviour. As a consequence, in addition to or as combination with longitudinal assessments, randomised experimental designs should be used in follow-up research, which either strengthen informational self-efficacy and examine its impact on media exposure, knowledge, and behaviour, or convey knowledge and examine its impact on informational self-efficacy-compared to a control group.

Second, we would like to critically reflect on our measures. Due to the programming mistake, the behavioural knowledge measure was limited to action knowledge and lacked knowledge about the relative effectiveness of different climate-related actions (see Frick et al. 2004). Moreover, the item number of seven was thereby relatively low which compromises reliability. A follow-up study should use and validate the extended version of the scale. A further limitation of our knowledge measure is that it merely encompasses factual knowledge questions and could be complemented with an assessment of knowledge structure (see, e.g. Eveland and Hively 2008). A respective measure could be adapted from prior approaches to assess political knowledge, such as knowledge structure density (e.g. Eveland and Schmitt 2015), or a combination of knowledge accuracy with knowledge complexity (e.g. Kahlor and Rosenthal 2009). Still, we would like to highlight that our assessment goes well beyond most existing studies, which often relied on people's own subjective knowledge ratings and did not differentiate system and behavioural knowledge.

Our measure of media exposure also needs critical reflection. With the applied measure, we only know how much contact people had with the issue of climate change. A first limitation of this approach is that we cannot differentiate between active information search and incidental news exposure (Boczkowski et al. 2018; Tewksbury et al. 2001). Hence, follow-up research could use a more fine-grained approach and assess both aspects separately. As an extension, people's attention to and elaboration of climate change-related information could be explicitly assessed in order to determine their degree of activity and motivation in dealing with the information (Eveland 2001; Oschatz et al. 2019). This extension is particularly important in light of Bandura's $(1977,1997)$ assumption that self-efficacy is specifically relevant for promoting active engagement in difficult behaviours. Accordingly, a follow-up study could investigate whether informational self-efficacy more strongly predicts active information search, and respective attention and elaboration, compared to incidental exposure to climate change-related information. Shehata et al. (2015) found that not only active information search but also incidental exposure to political information in the media predicts people's political knowledge (see also Tewksbury et al. 2001). Even though we assume that incidental exposure involves voluntariness (as it could also be intentionally ignored) and thus a certain degree of attention and elaboration, it might be more influenced by external factors such as social media algorithms and social influences compared to active information search. As a consequence, active information search might be more strongly related to knowledge acquisition and behaviour change.

Moreover, we do not know the exact contents of received media, namely whether they contained scientifically approved information or misinformation (van der Linden et al. 2017) 
or whether they were optimistic that climate change mitigation is possible. As misinformation might compromise knowledge acquisition and prior research has found that messages of scientific disagreement and uncertainty regarding effective courses of action might discourage engagement (Happer and Philo 2016), a closer look at media contents should be revealing. Hence, follow-up studies could use mixed methods approaches, combining survey data with content analyses of the used media (see, e.g. Barabas and Jerit 2009; Oschatz et al. 2019). The assessment could also cover prominent misinformation that is disseminated through media. However, a recent experiment by Drummond et al. (2020) gives rise to hope that exposure to fake news about climate change has only limited effects on recipients. Generally, also experimental research comparing the effects of different media contents will fruitfully extend our findings.

A further strand of research could investigate the communication of climate protective behaviours in media. Content analyses of climate change-related media coverage could investigate how and to what extent information on climate protective behaviours is provided. For example, analyses of Twitter data could be used to observe who responds how to which climate-relevant information (e.g. Jang and Hart 2015). Based on such insights, experimental research could compare different pre-existing or new ways of communicating behavioural information in their potential to foster recipients' respective knowledge, self-efficacy, and behavioural change.

Finally, frequency of media exposure might change over time and participants might have had different time periods in mind when answering the questions. Hence, in a follow-up, it could be valuable to explicitly ask participants to think about the last 6 months. In sum, we hope to encourage research that examines media exposure more in-depth — with regard to its different types and contents as well as with diverse methods. In our impression, specifically measures of media exposure still need to be further or newly developed as we did not come across convincing instruments through our literature search.

An interesting conceptual extension of our findings would be to include a measure of people's trust in science communication on climate change. Hocevar et al. (2014) found that social media self-efficacy predicted trustworthiness of information in social media. Hence, the question arises whether informational self-efficacy regarding climate change news might similarly predict trust in climate change communication, and whether strengthening informational self-efficacy might increase trust, which in turn might be a precondition for motivating impacts of climate change communication to unfold. Moreover, an assessment of political party affiliation might be a valuable addition in order to investigate whether the effectiveness of climate change communication might be limited to supporters of progressive parties (Tranter 2020).

\subsection{Practical implications}

We found that informational self-efficacy was related to media exposure regarding the issue of climate change, knowledge about the topic, and climate protective behaviour. Even though we do not know yet whether these relations are causal, we suggest to strengthen people's informational self-efficacy. In the following, we provide some ideas which still require validation by future empirical research.

A first practical approach might be through media literacy trainings (for an overview, see Turner et al. 2017). Media literacy "centers on specific knowledge and skills that can help critical understanding and usage of the media" (Jeong et al. 2012, p. 455). Informational self- 
efficacy could be such a skill. In a meta-analysis of 51 intervention studies, Jeong et al. (2012) reported positive effects of media literacy trainings on outcomes such as media knowledge, an ability to critically reflect media contents, and self-efficacy regarding behaviours discussed in media. With regard to the topic climate change, Cooper (2011) recommended media literacy education as a key strategy to improve public acceptance of climate science. Damico and Panos (2018) showed that facilitating group deliberation helped students to more critically evaluate an online source which questioned the scientific consensus on climate change.

A second — or embedded - practical option to strengthen informational self-efficacy, and at the same time limit the influence of fake news, might be to promote critical thinking (e.g. Paul and Elder 2006). This suggestion is based on recent findings by Lutzke et al. (2019). They showed that providing guidelines for evaluating online news on climate change reduced the likelihood that participants trusted, liked, and shared fake news about climate change, while at the same time their trusting, liking, and sharing of legitimate news were not diminished.

Disseminating guidelines for news evaluations could be complemented by creating room to discuss these news (e.g. in the context of a civil forum or a sustainability day organised by a municipality). We suppose that specifically the confidence to engage in debates might help individuals get actively involved in climate protection as indicated by the rather strong relation between the external dimension of informational self-efficacy and climate protective behaviour.

Finally, inferred from our finding that exposure to climate change-related information in the media was unrelated to climate protective behavioural knowledge, we recommend that climate change communication should more often not only explain the climate change phenomenon and its causes and consequences to the audience but also provide useful practical guidelines which behaviours help to mitigate climate change.

\section{Conclusion}

We found that people's subjective capability of informing themselves satisfactorily about climate change (i.e. informational self-efficacy) to reach goals like forming an opinion, evaluating political decisions regarding climate change, or determining true facts about the topic predicted their exposure to climate change communication in the media. It was also positively related to their knowledge about the climate system and climate protective behaviours, and the extent to which they actually engaged in climate protective actions. Informational self-efficacy positively predicted climate protective behaviour and climate system knowledge indirectly through media exposure - but not behavioural knowledge. Based on these findings, we suggest to strengthen people's confidence in dealing with climate change communication through media literacy trainings and examine the causal effect of these trainings on informational self-efficacy and climate change engagement. Furthermore, the impact of different behaviours on climate change should be more often and more concretely discussed in media coverage to convey more behavioural knowledge.

Supplementary Information The online version contains supplementary material available at https:/doi. org/10.1007/s10584-020-02918-9.

Acknowledgments We would like to thank Patrick Fissler, Doris Teutsch, and Sabine Trepte for their feedback on the study design, Elisabeth Prestele and Philipp Masur for their statistical advice, and three anonymous reviewers for their critical and exceptionally constructive questions and advice. 
Funding Open Access funding enabled and organized by Projekt DEAL.

Open Access This article is licensed under a Creative Commons Attribution 4.0 International License, which permits use, sharing, adaptation, distribution and reproduction in any medium or format, as long as you give appropriate credit to the original author(s) and the source, provide a link to the Creative Commons licence, and indicate if changes were made. The images or other third party material in this article are included in the article's Creative Commons licence, unless indicated otherwise in a credit line to the material. If material is not included in the article's Creative Commons licence and your intended use is not permitted by statutory regulation or exceeds the permitted use, you will need to obtain permission directly from the copyright holder. To view a copy of this licence, visit http://creativecommons.org/licenses/by/4.0/.

\section{References}

Arlt D, Hoppe I, Wolling J (2010) Klimawandel und Mediennutzung. Wirkungen auf Problembewusstsein und Handlungsabsichten [Climate change and media use. Impacts on problem awareness and behavioural intentions]. M\&K Medien \& Kommunikationswissenschaft 58(1):3-25. https://doi.org/10.5771/1615-634 $\mathrm{x}-2010-1-3$

Arlt D, Hoppe I, Schmitt JB, de Silva-Schmidt F, Brüggemann M (2018) Climate engagement in a digital age: exploring the drivers of participation in climate discourse online in the context of COP21. Environ Commun 12(1):84-98. https://doi.org/10.1080/17524032.2017.1394892

Bamberg S, Möser G (2007) Twenty years after Hines, Hungerford, and Tomera: a new meta-analysis of psychosocial determinants of pro-environmental behaviour. J Environ Psychol 27(1):14-25. https://doi.org/10.1016 /j.jenvp.2006.12.002

Bandura A (1977) Self-efficacy: toward a unifying theory of behavioral change. Psychol Rev 84(2):191-215. https://doi.org/10.1037/0033-295X.84.2.191

Bandura A (1997) Self-efficacy: the exercise of control. Freeman \& Company

Barabas J, Jerit J (2009) Estimating the causal effects of media coverage on policy-specific knowledge. Am J Polit Sci 53(1):73-89. https://doi.org/10.1111/j.1540-5907.2008.00358.x

Boczkowski PJ, Mitchelstein E, Matassi M (2018) "News comes across when I'm in a moment of leisure": understanding the practices of incidental news consumption on social media. New Media Soc 20(10):35233539. https://doi.org/10.1177/1461444817750396

Bond TG, Fox CM (2007) Applying the Rasch model: fundamental measurement in the human sciences, 2nd edn. Routledge

Bronstein J (2014) The role of perceived self-efficacy in the information seeking behavior of library and information science students. J Acad Librariansh 40(2):101-106. https://doi.org/10.1016/j. acalib.2014.01.010

Brüggemann M, Neverla I, Hoppe I, Walter S (2018) Klimawandel in den Medien [climate change in the media]. In: Meinke I, Claußen M, Storch HV (eds) Hamburger Klimabericht - Wissen über Klima, Klimawandel und Auswirkungen in Hamburg und Norddeutschland [Hamburg climate report - knowledge about climate, climate change, and its consequences in Hamburg and Northern Germany]. Springer Spektrum, pp 243-254

Budescu DV, Broomell SB, Por H-H (2009) Improving communication of uncertainty in the reports of the Intergovernmental Panel on Climate Change. Psychol Sci 20(3):299-308. https://doi.org/10.1111/j.14679280.2009.02284.x

Caprara GV, Vecchione M, Capanna C, Mebane M (2009) Perceived political self-efficacy: theory, assessment, and applications. Eur J Soc Psychol 39(6):1002-1020. https://doi.org/10.1002/ejsp.604

Capstick SB, Pidgeon NF (2014) What is climate change scepticism? Examination of the concept using a mixed methods study of the UK public. Glob Environ Chang 24:389-401. https://doi.org/10.1016/j. gloenvcha.2013.08.012

Capstick SB, Whitmarsh L, Poortinga W, Pidgeon NF, Upham P (2015) International trends in public perceptions of climate change over the past quarter century. Wiley Interdiscip Rev Clim Chang 6(1):35-61. https://doi.org/10.1002/wcc.321

Chen M-F (2015) Self-efficacy or collective efficacy within the cognitive theory of stress model: which more effectively explains people's self-reported proenvironmental behavior? J Environ Psychol 42:66-75. https://doi.org/10.1016/j.jenvp.2015.02.002

Cooper CB (2011) Media literacy as a key strategy toward improving public acceptance of climate change science. BioScience 61(3):231-237. https://doi.org/10.1525/bio.2011.61.3.8

Corner A, Clarke J (2017) Talking climate: from research to practice in public engagement. Palgrave Macmillan 
Curry J (2011) Reasoning about climate uncertainty. Clim Chang 108(4):723-732. https://doi.org/10.1007 /s10584-011-0180-Z

Damico JS, Panos A (2018) Civic media literacy as 21st century source work: future social studies teachers examine web sources about climate change. J Soc Stud Res 42(4):345-359. https://doi.org/10.1016/j. jssr.2017.10.001

Díaz-Siefer P, Neaman A, Salgado E, Celis-Diez J, Otto S (2015) Human-environment system knowledge: a correlate of pro-environmental behavior. Sustainability 7(12):15510-15526. https://doi.org/10.3390 $/$ su71115510

Doherty KL, Webler TN (2016) Social norms and efficacy beliefs drive the alarmed segment's public-sphere climate actions. Nat Clim Chang 6(9):879-884. https://doi.org/10.1038/NCLIMATE3025

Drummond C, Siegrist M, Árvai J (2020) Limited effects of exposure to fake news about climate change. Environ Res Commun 2(8):81003. https://doi.org/10.1088/2515-7620/abae77/pdf

Eastin MS, LaRose R (2000) Internet self-efficacy and the psychology of the digital divide. J Comput-Mediat Commun 6(1). https://doi.org/10.1111/j.1083-6101.2000.tb00110.x

Eveland WPJ (2001) The cognitive mediation model of learning from the news: evidence from nonelection, offyear election, and presidential election contexts. Commun Res 28(5):571-601. https://doi.org/10.1177 /009365001028005001

Eveland WPJ, Hively MH (2008) Political knowledge. In: Donsbach W (ed) The international encyclopedia of communication, pp 3715-3719 Wiley-Blackwell

Eveland WPJ, Schmitt JB (2015) Communication content and knowledge content matters: integrating manipulation and observation in studying news and discussion learning effects. J Commun 65(1):170-191. https://doi.org/10.1111/jcom.12138

Frick J, Kaiser FG, Wilson M (2004) Environmental knowledge and conservation behavior: exploring prevalence and structure in a representative sample. Personal Individ Differ 37:1597-1613. https://doi.org/10.1016/j. paid.2004.02.015

Geiger N, Swim JK, Fraser J (2017) Creating a climate for change: interventions, efficacy and public discussion about climate change. J Environ Psychol 51:104-116. https://doi.org/10.1016/j.jenvp.2017.03.010

Gil de Zúñiga H, Weeks B, Ardèvol-Abreu A (2017) Effects of the news-finds-me perception in communication: social media use implications for news seeking and learning about politics. J Comput-Mediat Commun 22(3):105-123. https://doi.org/10.1111/jcc4.12185

Hair JF, Black WC, Babin BJ, Anderson RE (2014) Multivariate data analysis, 7th edn Pearson Education Limited

Hamann KRS, Reese G (2020) My influence on the world (of others): goal efficacy beliefs and efficacy affect predict private, public, and activist pro-environmental behavior. J Soc Issues 76(1):35-53. https://oi. org/10.1111/josi.12369

Hanss D, Böhm G (2010) Can I make a difference? The role of general and domain-specific self-efficacy in sustainable consumption decisions. Umweltpsychologie 14:46-74

Happer C, Philo G (2016) New approaches to understanding the role of the news media in the formation of public attitudes and behaviours on climate change. Eur J Commun 31(2):136-151. https://doi.org/10.1177 /0267323115612213

Hart PS, Feldman L (2016) The impact of climate change-related imagery and text on public opinion and behavior change. Sci Commun 38(4):415-441. https://doi.org/10.1177/1075547016655357

Ho SS, Detenber BH, Rosenthal S [Sonny], \& Lee EWJ (2014) Seeking information about climate change: effects of media use in an extended PRISM. Sci Commun 36(3):270-295. https://doi.org/10.1177 $/ 1075547013520238$

Hocevar KP, Flanagin AJ, Metzger MJ (2014) Social media self-efficacy and information evaluation online. Comput Hum Behav 39:254-262. https://doi.org/10.1016/j.chb.2014.07.020

Hofstetter CR, Zuniga S, Dozier DM (2001) Media self-efficacy: validation of a new concept. Mass Commun Soc 4(1):61-76. https://doi.org/10.1207/S15327825MCS0401_05

Homburg A, Stolberg A (2006) Explaining pro-environmental behavior with a cognitive theory of stress. J Environ Psychol 26(1):1-14. https://doi.org/10.1016/j.jenvp.2006.03.003

Horn JL (1965) A rationale and test for the number of factors in factor analysis. Psychometrika 30(2):179-185. https://doi.org/10.1007/BF02289447

Hornsey MJ, Harris EA, Bain PG, Fielding KS (2016) Meta-analyses of the determinants and outcomes of belief in climate change. Nat Clim Chang 6:622-626. https://doi.org/10.1038/nclimate2943

Huang H (2016) Media use, environmental beliefs, self-efficacy, and pro-environmental behavior. J Bus Res 69(6):2206-2212. https://doi.org/10.1016/j.jbusres.2015.12.031

IPCC (2018) Global warming of $1.5^{\circ} \mathrm{C}$ : An IPCC special report on the impacts of global warming of $1.5^{\circ} \mathrm{C}$ above pre-industrial levels and related global greenhouse gas emission pathways, in the context of strengthening the global response to the threat of climate change, sustainable development, and efforts to eradicate poverty. 
Intergovernmental Panel on Climate Change. https:/www.ipcc.ch/site/assets/uploads/sites/2/2019/06/SR15 Full Report High Res.pdf

Jang SM, Hart PS (2015) Polarized frames on "climate change" and "global warming" across countries and states: evidence from Twitter big data. Glob Environ Chang 32:11-17. https://doi.org/10.1016/j. gloenvcha.2015.02.010

Jeong S-H, Cho H, Hwang Y (2012) Media literacy interventions: a meta-analytic review. J Commun 62(3):454 472. https://doi.org/10.1111/j.1460-2466.2012.01643.x

Jiménez-Castillo D, Ortega-Egea JM (2015) Too positive to change? Examining optimism bias as a barrier to media effects on environmental activism. J Environ Psychol 43:216-225. https://doi.org/10.1016/j. jenvp.2015.07.004

Jugert P, Greenaway KH, Barth M, Büchner R, Eisentraut S, Fritsche I (2016) Collective efficacy increases proenvironmental intentions through increasing self-efficacy. J Environ Psychol 48:12-23. https://doi. org/10.1016/j.jenvp.2016.08.003

Kahlor, L., \& Rosenthal S [Sonny] (2009) If we seek, do we learn? Predicting knowledge of global warming. Sci Commun, 30(3), 380-414. https://doi.org/10.1177/1075547008328798

Kaiser FG, Frick J (2002) Entwicklung eines Messinstrumentes zur Erfassung von Umweltwissen auf der Basis des MRCML-Modells [Development of a measure to assess environmental knowledge on the basis of the MRCML model]. Diagnostica 48(4):181-189. https://doi.org/10.1026//0012-1924.48.4.181

Kaiser FG, Wilson M (2000) Assessing people's general ecological behavior: a cross-cultural measure. J Appl Soc Psychol 30(5):952-978. https://doi.org/10.1111/j.1559-1816.2000.tb02505.x

Kaiser FG, Wilson M (2004) Goal-directed conservation behavior: the specific composition of a general performance. Personal Individ Differ 36(7):1531-1544. https://doi.org/10.1016/j.paid.2003.06.003

Kim Y, Choi SM (2005) Antecedents of green purchase behavior: an examination of collectivism, environmental concern, and PCE. Adv Consum Res 32:592-599. http://acrwebsite.org/volumes/9156/volumes/v32/NA-32

Klöckner CA (2013) A comprehensive model of the psychology of environmental behaviour - a meta-analysis. Glob Environ Chang 23(5):1028-1038. https://doi.org/10.1016/j.gloenvcha.2013.05.014

Lee Y-k, Kim S, Kim M-s, Choi J-g (2014) Antecedents and interrelationships of three types of pro-environmental behavior. J Bus Res 67(10):2097-2105. https://doi.org/10.1016/j.jbusres.2014.04.018

Leiner DJ (2013) Too fast, too straight, too weird: post hoc identification of meaningless data in internet surveys. Ludwig-Maximilian-University Munich https://www.researchgate.net/publication/258997762_Too_Fast_ Too_Straight_Too_Weird_Post_Hoc_Identification_of_Meaningless_Data_in_Internet_Surveys

Leiner D (2019) SoSci Survey (Version 3.1.06) [Computer software]. https://www.soscisurvey.de

van der Linden S, Leiserowitz A, Rosenthal, S [Seth], \& Maibach, E. (2017) Inoculating the public against misinformation about climate change. Global Chall 1(2):1-7. https://doi.org/10.1002/gch2.201600008

Loy LS (2018) Communicating climate change. How proximising climate change and global identity predict engagement [Dissertation]. Universität Hohenheim, Stuttgart

Loy LS, Masur PK, Schmitt JB, Mothes C (2019) Psychological predictors of political internet use and political knowledge in light of the perceived complexity of political issues. Inf Commun Soc 22(12):1733-1750. https://doi.org/10.1080/1369118X.2018.1450886

Lutzke L, Drummond C, Slovic P, Árvai J (2019) Priming critical thinking: simple interventions limit the influence of fake news about climate change on Facebook. Glob Environ Chang 58, online first. https://oi. org/10.1016/j.gloenvcha.2019.101964

Maibach EW, Myers TA, Leiserowitz AA (2014) Climate scientists need to set the record straight: there is a scientific consensus that human-caused climate change is happening. Earth's Future 2(5):295-298. https://doi.org/10.1002/2013EF000226

Moser SC (2010) Communicating climate change: history, challenges, process and future directions. Wiley Interdiscip Rev Clim Chang 1(1):31-53. https://doi.org/10.1002/wcc.11

Oeldorf-Hirsch A (2018) The role of engagement in learning from active and incidental news exposure on social media. Mass Commun Soc 21(2):225-247. https://doi.org/10.1080/15205436.2017.1384022

Oschatz C (2018) Wissen im Wandel: Der Einfluss der Klimaberichterstattung auf den klimapolitischen Wissenserwerb [Changing knowledge. The impact of climate news coverage on climate political knowledge acquisition]. Springer Fachmedien. https://doi.org/10.1007/978-3-658-18832-0

Oschatz C, Maurer M, Haßler J (2019) Learning from the news about the consequences of climate change: an amendment of the cognitive mediation model. J Sci Commun 18(2). https://doi.org/10.22323/2.18020207

Patt AG, Weber EU (2014) Perceptions and communication strategies for the many uncertainties relevant for climate policy. Wiley Interdiscip Rev Clim Chang 5(2):219-232. https://doi.org/10.1002/wcc.259

Paul R, Elder L (2006) The miniature guide to critical thinking. Concepts and tools. Foundation for critical thinking. https://www.criticalthinking.org/files/Concepts_Tools.pdf

Pingree RJ (2011) Effects of unresolved factual disputes in the news on epistemic political efficacy. J Commun 61(1):22-47. https://doi.org/10.1111/j.1460-2466.2010.01525.x 
Pingree RJ, Hill M, McLeod DM (2013) Distinguishing effects of game framing and journalistic adjudication on cynicism and epistemic political efficacy. Commun Res 40(2):193-214. https://doi.org/10.1177 /0093650212439205

Pingree RJ, Brossard D, McLeod DM (2014) Effects of journalistic adjudication on factual beliefs, news evaluations, information seeking, and epistemic political efficacy. Mass Commun Soc 17(5):615-638. https://doi.org/10.1080/15205436.2013.821491

Reese G, Junge E (2017) Keep on rockin' in a (plastic-)free world: collective efficacy and pro-environmental intentions as a function of task difficulty. Sustainability 9(2):1-12. https://doi.org/10.3390/su9020200

Ripple WJ, Wolf C, Newsome TM, Galetti M, Alamgir M, Crist E, Mahmoud MI, Laurance WF (2017) World scientists' warning to humanity: a second notice. BioScience 67(12):1026-1028. https://doi.org/10.1093 /biosci/bix 125

Ryghaug M, Holtan Sørensen K, Næss R (2011) Making sense of global warming: Norwegians appropriating knowledge of anthropogenic climate change. Public Underst Sci 20(6):778-795. https://doi.org/10.1177 $/ 0963662510362657$

Schafer JL, Graham JW (2002) Missing data: our view of the state of the art. Psychol Methods 7(2):147-177. https://doi.org/10.1037/1082-989x.7.2.147

Schenk NJ, Lensink SM (2007) Communicating uncertainty in the IPCC's greenhouse gas emissions scenarios. Clim Chang 82(3/4):293-308. https://doi.org/10.1007/s10584-006-9194-3

Schmidt A, Ivanova A, Schäfer MS (2013) Media attention for climate change around the world: a comparative analysis of newspaper coverage in 27 countries. Glob Environ Chang 23(5):1233-1248. https://oi. org/10.1016/j.gloenvcha.2013.07.020

Schmitt JB, Debbelt CA, Schneider FM (2018) Too much information? Predictors of information overload in the context of online news exposure. Inf Commun Soc 21(8):1151-1167. https://doi.org/10.1080/1369118 X.2017.1305427

Shehata A, Hopmann DN, Nord L, Höijer J (2015) Television channel content profiles and differential knowledge growth: a test of the inadvertent learning hypothesis using panel data. Polit Commun 32(3): 377-395. https://doi.org/10.1080/10584609.2014.955223

Shi J, Visschers VHM, Siegrist M (2015) Public perception of climate change: the importance of knowledge and cultural worldviews. Risk Anal 35(12):2183-2201. https://doi.org/10.1111/risa.12406

Shome D, Marx SM (2009) The psychology of climate change communication: a guide for scientists, journalists, educators, political aides, and the interested public. Center of Research on Environmental Decisions. Columbia University, New York, NY http:/guide.cred.columbia.edu/pdfs/CREDguide_full-res.pdf

Slater MD (2007) Reinforcing spirals: the mutual influence of media selectivity and media effects and their impact on individual behavior and social identity. Commun Theory 17(3):281-303. https://doi.org/10.1111 j.1468-2885.2007.00296.x

Stamm KR, Clark F, Eblacas PR (2000) Mass communication and public understanding of environmental problems: the case of global warming. Public Underst Sci 9(3):219-237. https://doi.org/10.1088/0963-6625 /9/3/302

Sterman JD (2011) Communicating climate change risks in a skeptical world. Clim Chang 108(4):811-826. https://doi.org/10.1007/s10584-011-0189-3

Stern PC (2000) New environmental theories: toward a coherent theory of environmentally significant behavior. J Soc Issues 56(3):407-424. https://doi.org/10.1111/0022-4537.00175

Taddicken M (2013) Climate change from the user's perspective: the impact of mass media and internet use and individual and moderating variables on knowledge and attitudes. J Media Psychol 25(1):39-52. https://doi. org/10.1027/1864-1105/a000080

Tewksbury D, Weaver AJ, Maddex BD (2001) Accidentally informed: incidental news exposure on the World Wide Web. J Mass Commun Q 78(3):533-554. https://doi.org/10.1177/107769900107800309

Tobler C, Visschers VHM, Siegrist M (2012) Consumers' knowledge about climate change. Clim Chang 114(2): 189-209. https://doi.org/10.1007/s10584-011-0393-1

Tranter B (2020) Does public knowledge of climate change really matter in Australia? Environ Commun 14(4): 537-554. https://doi.org/10.1080/17524032.2019.1696853

Tranter B, Booth K (2015) Scepticism in a changing climate: a cross-national study. Glob Environ Chang 33 : 154-164. https://doi.org/10.1016/j.gloenvcha.2015.05.003

Trepte S, Loy L, Schmitt JB, Otto S (2017) Hohenheimer Inventar zum Politikwissen (HIP). Konstruktion und Skalierung [Hohenheim Inventory on Political Knowledge (HIP). Construction and scaling.]. Diagnostica 63(3):206-218. https://doi.org/10.1026/0012-1924/a000180

Turner KH, Jolls T, Hagerman MS, O’Byrne W, Hicks T, Eisenstock B, Pytash KE (2017) Developing digital and media literacies in children and adolescents. Pediatrics 140:122-126. https://doi.org/10.1542/peds.2016$1758 \mathrm{P}$ 
Wang ES-T, Lin H-C (2017) Sustainable development: the effects of social normative beliefs on environmental behaviour. Sustain Dev 25(6):595-609. https://doi.org/10.1002/sd.1680

Whitmarsh L, Lorenzoni I (2010) Perceptions, behavior and communication of climate change. Wiley Interdiscip Rev Clim Chang 1(2):158-161. https://doi.org/10.1002/wcc.7

Whitmarsh, L., O’Neill, S. J., \& Lorenzoni, I. (Eds.). (2011). Engaging the public with climate change: behaviour change and communication. Earthscan

Wibeck V (2014) Enhancing learning, communication and public engagement about climate change - some lessons from recent literature. Environ Educ Res 20(3):387-411. https://doi.org/10.1080 $/ 13504622.2013 .812720$

Williams DM, Rhodes RE (2016) The confounded self-efficacy construct: conceptual analysis and recommendations for future research. Health Psychol Rev 10(2):113-128. https://doi.org/10.1080 $/ 17437199.2014 .941998$

Yohe G, Oppenheimer M (2011) Evaluation, characterization, and communication of uncertainty by the intergovernmental panel on climate change - an introductory essay. Clim Chang 108(4):629-639. https://doi.org/10.1007/s10584-011-0176-8

Zhao X (2009) Media use and global warming perceptions: a snapshot of the reinforcing spirals. Commun Res 36(5):698-723. https://doi.org/10.1177/0093650209338911

Publisher's note Springer Nature remains neutral with regard to jurisdictional claims in published maps and institutional affiliations.

\title{
Affiliations
}

\section{Laura S. Loy ${ }^{1} \cdot$ Karen R. S. Hamann ${ }^{1} \cdot$ Gerhard Reese $^{1}$}

\author{
Karen R. S. Hamann \\ hamann@uni-landau.de \\ Gerhard Reese \\ reese@uni-landau.de
}

1 Department of Social, Environmental and Economic Psychology, Faculty of Psychology, University of Koblenz-Landau, Fortstraße 7, 76829 Landau, Germany 